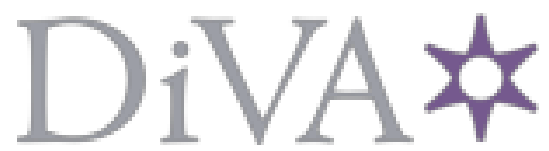

http://www.diva-portal.org

This is a report published by HUI Research

Citation for the original published report:

Bergman, M.,Rudholm, N. \& Granlund, D. (2014)

Reforming the Swedish pharmaceuticals market : Consequences for costs per

defineddaily dose. Stockholm : HUI Research. (HUI Working Papers ; 105)

N.B. When citing this work, cite the original published report.

Permanent link to this version:

http://urn.kb.se/resolve?urn=urn:nbn:se:sh:diva-25756 


\title{
Reforming the Swedish pharmaceuticals market - consequences for costs per defined daily dose
}

\section{Mats A. Bergman ${ }^{*}$, David Granlund ${ }^{\uparrow}$ and Niklas Rudholm ${ }^{\uparrow}$}

\begin{abstract}
Introduction: In 2009, the Swedish pharmaceuticals market was reformed. One of the stated policy goals was to achieve low costs for pharmaceutical products dispensed in Sweden.

Methods: Prices and sales data for off-patent brand-name and generic pharmaceuticals have been collected, and a log-linear regression model was used to estimate how the policy changes affected the cost per defined daily dose.

Results: The estimated effect is a 19 percent cost reduction per defined daily dose at the retail level and a 35 percent reduction in the prices at the wholesale level (pharmacies' purchase prices). The empirical results suggest that half of the retail-level price reduction is due to the introduction of a price cap for products going off patent and half is due to other components of the reform. Measured at the wholesale level the latter effect is larger than the former.

Conclusion: The reforms reduced the cost per defined daily dose for consumers while being advantageous also for the pharmacies, who saw their retail margins increase due to the reform. However, pharmaceutical firms supplying off-patent pharmaceuticals experienced a clear reduction in the price received for their products.
\end{abstract}

Keywords: Pharmaceutical industry, national pharmacy monopoly, pharmacy deregulation, competition, generics, pricing

JEL codes : D80, D83, L65, I11

*HUI Research, SE - 10329 Stockholm, Sweden, and Södertörn University, SE - 14189 Huddinge, Sweden.

${ }^{\uparrow}$ Department of Economics, Umeå University, SE - 90187 Umeå, Sweden.

$\underline{\uparrow}$ HUI Research, SE - 10329 Stockholm, Sweden, and the School of Technology and Business Studies, Dalarna University, SE - 79188 Falun, Sweden. Corresponding author: Niklas Rudholm, e-mail: nru@du.se. Phone: +46 706254627. 


\section{Introduction}

All European governments have regulated their pharmaceutical markets more or less extensively. Safety-in-use regulation is ubiquitous as is some form of economic regulation. A common argument for the latter is that a free market would lead to inequalities in access and out-of pocket costs for pharmaceuticals [1]. Many countries, including Iceland, Norway and Sweden in the Nordic region, have or have had rules that directly or indirectly regulate the number of pharmacies that are allowed to operate. In Sweden, a government-owned monopoly (Apoteket AB) was responsible for retail sales of pharmaceuticals since 1969.

Recently, the effectiveness of government intervention, whether in the form of regulation or ownership, has been challenged - in the pharmaceuticals market as well as in other markets. Regulation has been rolled back from markets and market segments where it has not been seen as critical and only retained where market failure was considered inevitable. Thus, the three mentioned Nordic countries have all deregulated their pharmacy markets during the last two decades, while retaining or developing regulation of pharmaceutical pricing. Inefficient regulation of pharmacies was considered to result in weak cost control and low availability of pharmacy services.

In 1996, Iceland was the first Nordic country to deregulate entry into the pharmacy market. After the reforms, the pharmacy manager still had to be a licensed pharmacist, but anyone could own the pharmacy. After the deregulation, the number of pharmacies increased by 41 percent in Iceland as a whole, and by as much as 67 percent in Reykjavik [1]. However, a related study also reports that the out-of-pocket costs for pharmaceuticals did not decrease as expected after the reform [2].

Then, in March 2001, the Norwegian market was deregulated in a manor similar to the Icelandic market. Before the reform, new entrants into the pharmacy market had to be approved by the Norwegian government, and the owner had to be a licensed pharmacist. After the reform, anyone can apply for a license to own a pharmacy, except prescribing physicians and pharmaceutical firms. The effect of the Norwegian reform has been studied by several authors $[4,5,6,7]$. The findings indicate that neither pharmacy costs nor pharmaceutical prices have decreased, but that availability to pharmacy services increased through an increase in the number of pharmacies and their opening hours. However, in a related study [8], the majority of the pharmacists surveyed reported that the workload had increased significantly after the deregulation of the market, and 40 percent of the pharmacists surveyed considered the workload to be "unacceptable" after the reform.

The Swedish pharmacy market, a national monopoly since 1969, remained closed to entry until 2009, although partial reforms of the pharmaceuticals market were introduced earlier. In 2002, generic 
substitution in combination with a national marketplace for generics was introduced in Sweden. In 2009, the Swedish pharmaceuticals retail market was finally reformed more fundamentally. The Swedish government set up five policy goals for the reform [9]: 1) increased availability to pharmaceuticals, 2) better service at the pharmacies, 3) low costs for pharmaceuticals, 4) maintained competence and safety in pharmaceutical supply and, finally, 5) a better use of pharmacies to promote a more efficient use of pharmaceuticals.

The means used to achieve these goals were privatization of pharmacies, a tightening of the price-cap for generics, more stringent rules for generic substitutions - in combination with a widening of the spread between the retail and wholesale prices, i.e., the pharmacies' margin. Effectively, the reform package shifted net revenues from the suppliers of pharmaceuticals to the pharmacies, in the expectation that this would boost the number of pharmacies. ${ }^{1}$ After four years, the number of pharmacies had increased by 40 percent; more in the larger cities and less in more sparsely populated regions [11].

The purpose of this paper is to investigate if and to what extent the policy reforms made in 2009 archived the third goal, that of low costs for pharmaceuticals in the Swedish market. We will thus empirically study how the 2009 reforms affected the costs per dispensed defined daily dose (DDD) in Sweden. Since the reform mainly had consequences for the generics market (i.e., the market for offpatent drugs), we focus on this segment. We are able to divide the total reform effect into two parts, one general reform effect affecting all generic drugs, and one effect working specifically through the introduction of a price cap for products going off patent.

Our results show that the reforms have been effective in delivering lower costs per DDD in the Swedish market. The retail price per DDD fell by 19 percent and the wholesale price fell by 35 percent. The results also indicate that, at the retail level, the price-cap effect and the general reform effect account for roughly half of the total price effect each, while at the wholesale level the effect stemming from the price cap is somewhat smaller than the general reform effect. That the relative importance of the price cap is larger for retail prices is partially a mechanical consequence of how the pharmacy (retail) margin is calculated, and partially due to the decision to increase the retail margin by 10 SEK per package ( 10 SEK $\approx 1.10$ EURO, exchange rate 2014-06-02) for off-patent products exposed to generic competition, as part of the reform. ${ }^{2}$

\footnotetext{
${ }^{1}$ In addition, the reform package contained elements that likely also shifted net revenues from other retailers and from parallel traders to pharmacies.

${ }^{2}$ This increase corresponds to an increase by about $13 \%$ of the net revenues for all Swedish pharmacies combined on sales of pharmaceuticals within the pharmaceuticals insurance system [11].
} 


\section{Material and methods}

\subsection{The reform}

Between 1969 and 2010 pharmaceuticals were sold exclusively in Sweden through a nationwide government-owned monopoly, the National Corporation of Swedish Pharmacies (NCSP). The NCSP's retail margin for prescription pharmaceuticals was regulated by the Swedish Dental and Pharmaceutical Benefits Board (DPBA), and an implication of the regulation was national pricing. As for the pharmaceutical firms in Sweden, they have formal had the right to set prices before as well as after the 2009 reforms. However, for a pharmaceutical to be included in the Swedish pharmaceuticals insurance (or patient reimbursement) system the prices have to pass a social cost-benefit test in order to receive authorization from the DPBA.

The 2009 reform consisted of a series of steps [10]. First, in July 2009, the price of off-patent products was capped at 35 percent of the price during the patent period if three conditions were fullfilled. First, an equivalent generic must have been sold at a price below 30 percent of the price during patent protection by a firm that achieved at least 10 percent of the sales within the exchange group. Second, there must have been positive generic sales each month for at least 4 months. Third, at least six months must have passed since generic competition was first established in the exchange group. Only when all three conditions are met will the price cap become effective and the price of the original article will then be capped at 35 percent of the original product's price at the time of generic entry.

Second, from November 1, 2009, the obligation to substitute towards the lowest-cost generic available at the individual pharmacy was changed to an obligation to dispense the lowest-cost generic substitute available in the Swedish market. The lowest-cost product, called "product of the month", is determined by the DPBA in an auction where the lowest bid wins. Simultaneously and as mentioned, the retail margin for prescription pharmaceuticals was increased with 10 SEK per package dispensed of exchangeable pharmaceutical products at the pharmacy. The retail margin for articles that have a defined exchange group (i.e. have competition from generics) is after the reforms thus set according to the following formulas;

Wholesale price $(\mathrm{WP}) \leq 75.00 \mathrm{SEK}$

Wholesale price $>75,00-300,00$ SEK

Wholesale price $>300,00-6000,00$ SEK

Wholesale price > 6000,00 SEK

$$
\begin{aligned}
& \text { Retail price }=(\mathrm{WP} \times 1,20)+31.25 \mathrm{SEK}+10.00 \mathrm{SEK} \\
& \text { Retail price }=(\mathrm{WP} \times 1,03)+44,00 \mathrm{SEK}+10,00 \mathrm{SEK} \\
& \text { Retail price }=(\mathrm{WP} \times 1,02)+47,00 \mathrm{SEK}+10,00 \mathrm{SEK} \\
& \text { Retail price }=\mathrm{WP}+167,00 \mathrm{SEK}+10,00 \mathrm{SEK}
\end{aligned}
$$


while for products without competition, the last 10 SEK is not added to the retail margin. ${ }^{3}$ These formulas show that the retail margin always exceeded 31.25 SEK $(\approx 3.43$ EURO, exchange rate 201406-02), but never exceeded 177 SEK $(\approx 19.45$ EURO, exchange rate 2014-06-02) per package dispensed at the pharmacy during the period under study.

Third, in February 2010, following a decision by the Swedish parliament in April 2009, entry into pharmacy retailing was allowed and two thirds of all existing pharmacies where privatized. The majority of the privatized pharmacies were sold in blocks to private investors, while a fraction was reserved for small investors and one third remained government owned. The change in ownership became effective as of February 2010.

Prices on prescription pharmaceuticals are still regulated in Sweden and consequently pharmacies mainly compete in location and service quality, e.g. opening hours and in-store availability of pharmaceuticals, but also in the pricing of OTC-drugs and non-drug products.

Finally, in May 2010, following complaints that the manufacturer of the lowest-cost generic alternative sometimes ran out of stock, the pharmacies were allowed to dispense the second- or even third-lowest-cost generic - if the regulating authority declared a national stock-out of the first-hand choice.

\subsection{Data}

The dataset used in this study was collected by IMS Sweden and covers off-patent prescription pharmaceuticals, branded as well as generics, sold through pharmacies during the period January 1, 2006 through December 31, 2011. Prices and volumes are measured on the article level, i.e., a product with a certain active ingredient, strength, form and package size, supplied by a certain firm. Data also identify multi-dose dispensed drugs (MD drugs; see below). For any given article, retail prices are identical at all pharmacies. The volumes sold could, in principle, be measured at the individual pharmacy level, but were aggregated to the national level by IMS.

For each article, besides price and quantity, we know whether it belongs to the preferred (lowest price) provider (i.e. is the "product of the month") or the second- or third-hand choice; whether it was previously sold under a patent, is a branded generic or a true generic; and, if the product went off patent in 2004 or later, at what date this happened. Before the 2009 reforms, the exchange groups used in the substitution system were defined relative to the prescribed article, which normally means the original article. An exchange group comprised all articles with the same active ingredient, strength and

\footnotetext{
${ }^{3}$ The additional 10 SEK for exchangeable products was increased to 13 SEK in October 2013.
} 
form, for package sizes that deviated no more than 12 percent from that of the original article. ${ }^{4}$ However, this way of defining the exchange group was considered to be somewhat arbitrary and sometimes ambiguous. During 2010, the DPBA therefore pre-defined exchange groups with fixed package-size limits (e.g., packages with 14-16 pills were defined to belong to the exchange group T14; packages with 40-45 pills were defined to belong to the exchange group T19, etc.).

\subsection{Descriptive statistics}

Table 1 shows the average (sales-weighted) cost per defined daily dose (Cost/DDD) by exchange group in SEK for different time periods, calculated at the retail and wholesale level, either including or excluding MD drugs. MD drugs are individualized dosage bags, where each bag contains all pharmaceuticals that a particular individual need to consume at one specific moment in time. Every dosage bag is marked with the name of the patient, the content and the time at which it should be consumed. This segment comprises about 10 percent of the total market, with the remaining 90 percent consisting of regular prescriptions. The enhanced possibility to use package sizes and products that minimize costs when putting the dosage bags together may explain the somewhat lower average cost per DDD when MD is included, but the difference may also be due to a different average composition. The averages presented in the table indicate that the cost per DDD is somewhat higher directly after the reform. However, the averages also show a clear negative trend after the reform, and in the two last periods, average cost per DDD is clearly below what was recorded before the reform.

Table 1 about here.

\subsection{Empirical model}

The following log-linear regression model has been estimated:

Ln Cost $/ \mathrm{DDD}_{e t}=\alpha_{e}+\beta_{1}$ Trend $_{t}+\beta_{2}$ Dreform $_{t}+\beta_{3}$ DPS2009 $_{e t}+\beta_{4}$ Patent $_{\text {Trt }}+$

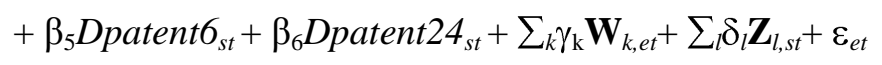

The dependent variable is the natural logarithm of the cost per DDD for exchange groups $e$ at time $t$. In this paper, an exchange group consists of all articles with the same active ingredient, strength and form, and within each exchange group there may be different package sizes.

The parameters to be estimated are $\alpha, \beta, \gamma$ and $\delta$. Subindex $s$ indicates pharmaceutical-substance level and thus takes the same value for all exchange groups with the same active substance. Parameters

\footnotetext{
${ }^{4}$ I.e., an original article with a certain substance, strength, and administrative form may be sold in a 100-pill unit; the exchange group will then consist of all articles with the same substance, strength, and administrative form that sell in packages ranging from 88 to 112 pills.
} 
capture exchange-group-specific fixed effects, included to ensure that our estimated reform effect has not been affected by the introduction or withdrawal of exchange groups from the market. Trend is a linear time trend and Dreform is an indicator variable taking the value 1 after the reform in November 2009, and 0 before that. In all estimations, a window excluding observations from the months when the reform was implemented, i.e. from November 2009 until April 2010, was used.

The indicator variable DPS2009 equals 1 for observations that could potentially be affected by the price cap. It is set equal to 1 for substances and months after June 2009 when at least six months have passed since patent expiration. I.e., we choose not to condition on whether the price cap is actually in effect, since this depends on generic entry and generic prices and is, therefore, endogenous. PatentTr is the number of month since patent expiration, but it is truncated at 24 months due to lack of reliable data on patent expirations before 2004. Dpatent6 and Dpatent24 are indicator variables equal to 1 if more than 6 or 24 months, respectively, have passed since patent expiration and 0 otherwise. ${ }^{5}$ The patent expiration variables have been included to capture potential short-term and long-term effects of patent expiration on the cost per DDD, in addition to the effect of the price cap. Note also that since no exchangeable products are under patent protection there is no need to control for current patent status.

The most general specification of our model, presented in eq. 1 above, also includes a vector $\mathbf{W}=\left(W_{l}\right.$, $\left.W_{2}, W_{3}, W_{4}\right)$ of variables that are included to control for the effects of different aspects of competition on the cost per DDD. The following variables are included: the number package sizes per exchange group, the number of exchange groups per pharmaceutical substance, the average number of firms for each package size in the exchange group and the number of firms per pharmaceutical substance. The vector $\mathbf{Z}$, finally, includes measures (at the substance level) of the number of therapeutic competitors and the number of therapeutic alternatives with generic versions.

The first vector of competition-related variables is potentially endogenous. Consequently we estimate versions of the model where we have excluded these variables from the regression equation. Although this alleviates the potential endogeneity problem, it might cause missing-variable bias, since we cannot control for the exogenous variation in these variables. In our opinion, the models where this vector of competition-related variables has been excluded still gives a better measure of the reform effect on the cost per DDD. These estimations also suggest how the exclusion of these variables may affect the estimated reform effect.

Equation (1) is estimated separately, first for retail and then for wholesale prices, as well as with and without MD. Our main model is marked Dreform in Tables 2 and 3. Here, the vector of possibly endogenous variables, $\boldsymbol{W}$, is excluded. We believe that the results from the estimation of this specification give the most accurate measure of the reform effect, given the setup of the reform and the

\footnotetext{
${ }^{5}$ See the results section for a discussion of how parameter estimates associated with these variables should be interpreted.
} 
data available for analysis.

The estimated total reform effect is the sum of a direct reform effect, measured by the parameter $\beta_{2}$, and the effect of the price cap, calculated as the $\beta_{3}$ parameter times the weighted average of the pricecap variable from July 2009. ${ }^{6}$ The total effect is thus the weighted average of the effect for those not affected be the price cap and for those that are. The parameter estimate for the total effect is reported at the bottom of the result tables.

\section{Results and discussion}

Table 2 presents estimation results for the retail prices, excluding and including MD drugs, respectively. Results for wholesale prices, excluding and including MD drugs are presented in Table 3. The first and third columns (marked Dreform, W) present our most general model, including the $\mathbf{W}$ and $\mathbf{Z}$ vectors of competition-related variables, while the second and forth columns (marked Dreform) only include the $\mathbf{Z}$ vector. In the discussion we focus on results related to Dreform. We prefer this model as it excludes the potentially endogenous variable vector, W. Note, however, that the different specifications and datasets used do not change the estimation results for our main variables of interest in any major way.

Table 2 about here.

In second column of Table 2, relating to our preferred model and when MD sales are excluded from the analysis, the estimates for the general reform effect are negative and statistically significant with a parameter estimate of approximately -0.11 . The estimate for the price cap is also negative with a parameter estimate of -0.11 and statistically significant. Using the formula for calculating the effect in percentage terms, $100 *[\exp (\beta)-1]$, this means that the estimated reform effects via the general reform effect and the introduction of the price cap, respectively, each corresponds to a $10 \%$ decrease in the cost per DDD. ${ }^{7}$

As mentioned above, PatentTr is the number of month since patent expiration, truncated at 24 , while Dpatent6 and Dpatent 24 are indicator variables equal to 1 if more than 6 or 24 months, respectively, have passed since the patent expired for substance $s$. These variables were included to capture potential effects of patent expiration on the cost per DDD. The parameter estimate related to PatentTr is negative and statistically significant at the 1 percent level in all estimated models. In our preferred model specification the parameter estimate for PatentTr indicates that the cost per DDD decreases with about 4 percent per month during the first two years after patent expiration. The negative point estimate for Dpatent6, while not statistically significant in our preferred specification, indicates that

\footnotetext{
${ }^{6}$ The post-reform average of the price-cap variable is 0.95 .

${ }^{7}$ The formula will be used throughout the paper to calculate the percentage price effects presented in the text.
} 
the cost declines more rapidly the first few months after patent expiration than the estimated $4 \%$ per month during the first two years. Our preferred model does, however, not indicate that there are any further cost reductions after 24 months. ${ }^{8}$

In Table 2 the total reform effect, presented at the bottom of the table, includes the direct reform effect on the cost per DDD as well as the effect through the price cap. In our preferred model the parameter estimate for the total reform effect is -0.21 , suggesting a total reform effect equal to a $19 \%$ decrease in the cost per DDD, again using the formula for calculating the percentage effect.

Turning to the last two columns of Table 2, where the pharmaceutical products that are sold as multidose dispensed drugs, MD, are also included in the sample, we find a slightly larger total reform effect, around 21 percent. Note also the similarities in the parameter estimates in all four specification, indicating that our results are not sensitive to changes in specification and/or the inclusion of MD in the sample.

The estimation results related to wholesale prices are presented in Table 3. The main differences between Table 2 (retail prices) and Tables 3 (wholesale prices) are that the latter point estimates are larger for the general effects of the reform and for the effects of the price cap, hence suggesting a larger total reform effect. A larger reform effect on wholesale prices is to be expected, since the reform package included an intentional increase in the retail margin by 10 SEK per dispensed package at the pharmacy, and since the algorithm used to calculate the retail margin (described on page 4, section 2.1 above) results in a less-than-proportional effect on retail prices when wholesale prices change.

The parameter estimate for the direct reform effect, reported in Table 3 to be -0.27 in our preferred model, corresponds to a direct reform effect of about $-24 \%$. The effect of the price cap corresponds to a reduction in the cost per DDD by almost $-16 \%$, for a total effect amounting to a reduction of the wholesale price by about $35 \%$. Finally, we see that including the MD part of the market again has a negligible effect on the estimates for the reform effect.

Table 3 about here.

\section{Conclusion}

In 2009, the Swedish pharmacy market was deregulated. During the period 1969 until 2010, pharmaceuticals were sold exclusively in Sweden through a nationwide government-owned monopoly,

\footnotetext{
${ }^{8}$ Controlling for the time since patent expiration more flexibly using, e.g., 24 indicator variables, results in very similar estimates for the coefficient of main interest, i.e., those associated with Dreform and DPS2009.
} 
but in February 2010 the previous monopoly was exposed to competition when entry into pharmacy retailing was allowed and two thirds of all existing government-owned pharmacies where privatized. However, the reform package also contained other regulatory changes, including the introduction of a price cap on off-patent products, stricter rules for generic substitution, and a widened retail margin for pharmacies. One of the stated policy goals was to achieve low costs for the pharmaceutical products dispensed in Sweden [4], and the purpose of our paper has been to investigate if this goal has been meet by the deregulation.

We have thus estimated the reform effect on the cost per dispensed DDD in the Swedish market. Our results show a total reform effect corresponding to a reduction of the cost per DDD by 19 percent at the retail level and by 35 percent at the wholesale level. The difference between these two measures is partly due to the regulatory algorithm that determines the retail margin, but it is also in part caused by the increased retail margin as part of the reform package. Each of the two effects that we estimated, a general reform effect and an effect from the introduction of a price cap, appear to account for approximately half of the total price-reducing effect each for the retail price, while at the wholesale level the effect through the price cap is somewhat smaller than the general reform effect.

Overall, the reform seems to have reduced pharmaceutical costs per DDD, hence benefiting consumers and tax payers, and it seems also to have been advantageous for the pharmacies through the increased retail margin that was part of the package. However, the reform also clearly reduced prices for the manufacturers of off-patent pharmaceuticals, both through the introduction of the price cap and due to the other price reducing effects stemming from the reform.

\section{Acknowledgements}

Financial support from the Swedish Competition Authority is gratefully acknowledged. We are also grateful to IMS Sweden and Tillväxtanalys for supplying the data used in this paper. 


\section{References}

[1] Almarsdottir AB, Morgall JM, Björnsdottir I. A question of emphasis: efficiency or equality in the provision of pharmaceuticals. Int J Health Plan M 2000; 15: 149-161.

DOI: 10.1002/1099-1751(200004/06)15:2<149::AID-HPM584>3.0.CO;2-Y

[2] Almarsdottir AB, Morgall JM, Grimsson A. Cost containment of pharmaceutical use in Iceland: the impact of liberalization and user charges. J Health Serv Res Po 2000; 2: 109-113.

DOI: $10.1177 / 135581960000500209$

[3] Handelns Utredningsinstitut (HUI). Den regelreformerade svenska läkemedelsmarknaden - Kan de direktiv som givits enmansutredaren leda fram till en konkurrensutsatt marknad?(in Swedish). HUI, 2007.

[4] Anell A, Hjelmgren J. Implementing competition in the pharmacy sector: lessons from Iceland and Norway, Appl Health Econ Health Policy 2002; 1: 149-156.

[5] Holmberg C, Kjellberg H, Axelsson B. Läkemedelsdistributionen i Norden - En komparativ studie av aktörer, resurser och aktiviteter (in Swedish). SSE/EFI Working Paper Series in Business Administration No 2003:10, 2003.

[6] Anell, A. Nya villkor för apotek och läkemedelsförsäljning - Erfarenheter från Danmark, Island och Norge (in Swedish). IHE Arbetsrapport 2004:2, 2004.

[7] Econ. Evaluering av apotekloven och indexprissystemet (in Norwegian). Rapport 2004:10, 2004.

[8] Rudholm N. Läkemedelsdistributionen i Finland, Norge och Sverige - an analys av distributionsledet (in Swedish). Konkurrensverkets uppdragsforskningsserie 2005:1, 2005.

[9] Statskontoret. En omreglerad apoteksmarknad (in Swedish). Slutrapport 2013:7, 2013.

[10] Tillväxtanalys. Apoteksmarknadens omreglering - Effekter på följsamhet, priser och kostnader per dagsdos (in Swedish). Working Paper 2012:19, 2012.

[11] Vårdanalys. Låt den rätte komma in. (in Swedish). Report 2014:3, 2014. 
Table 1: Descriptive statistics, SEK per DDD

\begin{tabular}{lrrrr}
\hline & Retail & Retail & Wholesale & Wholesale \\
\hline Period & Excl. MD & Incl. MD & Excl. MD & Incl. MD \\
\hline Pre reform: Jan. 2006 - June & 7.46 & 7.11 & 5.77 & 5.53 \\
2009 & & & \\
Post reform & & & \\
May 2010 -April 2011 & 7.82 & 7.45 & 6.00 & 5.74 \\
May 2010 -Dec. 2011 & 7.37 & 7.10 & 5.57 & 5.41 \\
Jan. 2011 - Dec. 2011 & 6.96 & 6.79 & 5.21 & 5.14 \\
Total sales, million of SEK, 2011 & 3755.90 & 4116.15 & 2018.82 & 2298.92 \\
\hline
\end{tabular}


Table 2: Estimation results, Cost per DDD, Retail prices, excluding and including sales of MD drugs.

\begin{tabular}{lllll}
\hline & $\begin{array}{l}\text { Dreform, W, } \\
\text { excl. MD }\end{array}$ & $\begin{array}{l}\text { Dreform, } \\
\text { excl. MD }\end{array}$ & $\begin{array}{l}\text { Dreform, W, } \\
\text { incl. MD }\end{array}$ & $\begin{array}{l}\text { Dreform, } \\
\text { incl. MD }\end{array}$ \\
\hline Trend & 0.000 & -0.000 & $0.003 * * *$ & $0.002^{* *}$ \\
Dreform & $(0.001)$ & $(0.001)$ & $(0.001)$ & $(0.001)$ \\
DPS2009 & $-0.084 * *$ & $-0.108 * * *$ & $-0.110^{* *}$ & $-0.127^{* * *}$ \\
& $(0.039)$ & $(0.041)$ & $(0.043)$ & $(0.042)$ \\
PatentTr & $-0.116 * * *$ & $-0.110^{* * *}$ & $-0.126 * * *$ & $-0.116^{* * *}$ \\
& $(0.036)$ & $(0.039)$ & $(0.036)$ & $(0.038)$ \\
Dpatent6 & $-0.039 * * *$ & $-0.044 * * *$ & $-0.041 * * *$ & $-0.044 * * *$ \\
Dpatent24 & $(0.008)$ & $(0.008)$ & $(0.009)$ & $(0.009)$ \\
& -0.134 & -0.127 & -0.121 & -0.121 \\
Reform effect & $(0.087)$ & $(0.091)$ & $(0.094)$ & $(0.097)$ \\
& -0.053 & 0.012 & -0.083 & -0.046 \\
RoBS & $(0.062)$ & $(0.059)$ & $(0.061)$ & $(0.060)$ \\
\hline
\end{tabular}

Note: The regression "Dreform, $W$ " includes all variables that control for competition, while all regressions include the measures of therapeutic competition. The 2008 levels of sales in the exchange groups are used as weights. ***, **, * indicate that the coefficient is statistically significant different from zero on the $1 \%$, $5 \%$ and $10 \%$ significance levels, respectively. 
Table 3: Estimation results, Cost per DDD, Wholesale prices, excluding and including MD sales.

\begin{tabular}{lllll}
\hline & $\begin{array}{l}\text { Dreform, W, } \\
\text { excl . MD }\end{array}$ & $\begin{array}{l}\text { Dreform, } \\
\text { excl . MD }\end{array}$ & $\begin{array}{l}\text { Dreform, W, } \\
\text { incl. MD }\end{array}$ & $\begin{array}{l}\text { Dreform, } \\
\text { incl. MD }\end{array}$ \\
\hline Trend & -0.000 & -0.001 & $0.002^{*}$ & 0.001 \\
Dreform & $(0.001)$ & $(0.001)$ & $(0.001)$ & $(0.001)$ \\
DPS2009 & $-0.229 * * *$ & $-0.266 * * *$ & $-0.231^{* * *}$ & $-0.252^{* * *}$ \\
& $(0.045)$ & $(0.054)$ & $(0.045)$ & $(0.048)$ \\
PatentTr & $-0.176 * * *$ & $-0.173 * * *$ & $-0.181^{* * *}$ & $-0.175^{* * *}$ \\
& $(0.046)$ & $(0.051)$ & $(0.044)$ & $(0.047)$ \\
Dpatent6 & $-0.046 * * *$ & $-0.051^{* * *}$ & $-0.048 * * *$ & $-0.051^{* * *}$ \\
& $(0.010)$ & $(0.010)$ & $(0.011)$ & $(0.010)$ \\
Dpatent24 & -0.145 & -0.132 & -0.124 & -0.120 \\
& $(0.120)$ & $(0.124)$ & $(0.124)$ & $(0.127)$ \\
\hline Reform effect & -0.064 & 0.020 & -0.093 & -0.048 \\
R & $(0.107)$ & $(0.100)$ & $(0.099)$ & $(0.097)$ \\
\hline NoBS & $-0.398 * * *$ & $-0.432 * * *$ & $-0.404 * * *$ & $-0.420 * * *$ \\
\hline
\end{tabular}

See note at the bottom of table 2. 